\title{
Un hallazgo lingüístico. Los trabajos de B. Mitre y S. Lafone Quevedo sobre la "Doctrina cristiana y catecismo en la lengua Allentiac" del padre Valdivia (1894 [1607])
}

\author{
Sofía De Mauro ${ }^{1}$ \\ Universidad Nacional de Córdoba \\ Instituto de Humanidades, Argentina
}

\begin{abstract}
Resumen
En 1894, el chileno José Toribio Medina publica en Sevilla una copia de la obra sobre la lengua allentiac del padre Luis de Valdivia SJ (1607), que hasta el momento se consideraba perdida. Esta obra fue la base de una serie de publicaciones a cargo de los principales referentes en Argentina de la americanística moderna. Samuel Lafone Quevedo escribe, entre septiembre y octubre en el diario La Nación, "Arte y vocabulario de la lengua Allentiac (Guarpe)". Por su parte, Bartolomé Mitre publica, también en 1894, en la Revista del Museo de La Plata un trabajo crítico sobre la obra de Valdivia, "Lenguas americanas. Estudio bibliográfico-lingüístico de las obras del P. Luis de Valdivia sobre el araucano y el allentiak, con un vocabulario razonado del allentiak".
\end{abstract}

1 Para correspondencia, dirigirse a: Sofía De Mauro (sofia.de.mauro@unc.edu.ar),Ciudad Universitaria, Pabellon Agustin Tosco, Córdoba, Argentina. ORCID 0000-0002-1767-0954. 
En este artículo, pretendemos mostrar una forma de trabajo que se consolida en la década de 1890 entre algunos actores de la lingüística (sud)americana. En este sentido, analizaremos el trasfondo de estas publicaciones a partir de intercambios personales (inéditos) que sostienen ambos estudiosos en el que construyen y reconstruyen datos y representaciones sobre las lenguas indígenas. El estudio, entonces, de algunos papeles de trabajo de los archivos de investigación de cada uno, junto a otro material publicado en distintos medios nos permitirá poner al descubierto la circulación de la información y la construcción colectiva del conocimiento lingüístico en Argentina.

Palabras clave: lingüística americana, lenguas indígenas, Bartolomé Mitre, Luis de Valdivia, Samuel Lafone Quevedo.

\author{
A linguistics Finding. The Works of B. Mitre and S. \\ LAFONE QUEVEDO ON THE "DoctRINA CRISTIANA Y CATECISMO \\ EN LA LENGUa AllentiaC” OF L. DE VAldivia (1894 [1607])
}

\title{
Abstract
}

In 1894, the chilean José Toribio Medina publishes, in Sevilla, a copy of the work of the priest Luis de Valdivia SJ on allentiac language (1607), which, until then, was thought to be missing. This work set the ground for a series of publications on the subject of allentiac, by the main argentinian referents in modern americanism. Samuel Lafone Quevedo writes, from september to october in the newspaper La Nación, the "Arte y vocabulario de la lengua Allentiac (Guarpe)". Bartolomé Mitre publishes, also in 1894, in the journal Revista del museo de La Plata a review of Valdivia's work, "American languages. A bibliographical and linguistic study of the works of P. Luis de Valdivia on araucanian and allentiak, with a reasoned vocabulary of allentiak".

In this article, we intend to reveal a manner of working that is consolidated in the decade of 1890 among some of the (sud)american linguistics main actors. We will analyze the background of these publications with personal (and unpublished) exchanges held by these two particular thinkers, in which they construct and reconstruct data and representations on indigenous languages. The study of some of each's papers, plus other material published in different media, will allow us to uncover the flow of information and the collective construction of linguistic knowledge in Argentina.

Keywords: American linguistics, indigenous languages, Bartolomé Mitre, Luis de Valdivia, Samuel Lafone Quevedo.

Recibido: $13 / 04 / 20$

Aceptado: 29/12/20 


\section{BARTOLOMÉ MITRE Y SAMUEL LAFONE QUEVEDO²}

En 1936, el antropólogo José Imbelloni describe, en la Introducción a "Los aborígenes prehispánicos e históricos", el estudio de las lenguas indígenas del territorio argentino hasta la época de Bartolomé Mitre (1821-1906) y Samuel Lafone Quevedo (1835-1920)3. Según el autor, las "disciplinas lingüísticas" se mantuvieron en un "estado embrionario", sin base científica, hasta bien entrado el siglo XIX. Es recién a fines de 1800 cuando, simultáneamente en América del Norte y América del Sur se puede "encontrar un movimiento real y amplio de renovación en la ciencia lingüística americana" (1936: 178). Mitre y Lafone Quevedo ocupan, para Imbelloni, un lugar significativo en el período de profesionalización de la lingüística americana en la Argentina y cada uno representa una forma de clasificación y reflexión sobre estas lenguas propia y original.

En cuanto al desarrollo de estos estudios en el mismo siglo, pero en América del Sur, este diagnóstico coincide parcialmente con el realizado, más de cuarenta años antes, por Diego Barros Arana y Rodolfo Lenz en "La lingüística americana. Su historia i estado actual" (1893). Allí hacen un estado de la cuestión del campo, y se pone en evidencia el vacío en la investigación sobre las lenguas de esta parte del continente. En ese sentido, si bien entre las décadas de 1870 y 1880 se reconocen una serie de debates y producciones relacionadas con las lenguas indígenas (Ennis 2018; Malvestitti 2020); hipotetizamos que es hacia mediados de la década de 1890 cuando se consolida una red colaborativa de reflexión y producción sobre las lenguas de esta parte del continente americano.

2 Este trabajo se enmarca en el Equipo de trabajo PICT 2015-1507: "Tecnologías de papel. Patrones para la documentación y comunicación científica de los estudios de lenguas indígenas de Patagonia y Tierra del Fuego, 1860-1930", dirigido por Marisa Malvestitti y Máximo Farro; y forma parte de la tesis doctoral "El Catálogo razonado de la sección Lenguas Americanas de Bartolomé Mitre y la lingüística americana" (2020, financiada por el CONICET). Una versión preliminar de este texto fue presentada junto a Luisa Domínguez en el $11^{\circ}$ Congreso Internacional de Lingüística Misionera, llevado a cabo en Santa Rosa del 3 al 5 de marzo del 2020. Agradezco a Máximo Farro por los comentarios y acompañamiento para el armado del artículo que aquí se presenta.

3 Se trata de un capítulo de la Historia de la Nación Argentina de Ricardo Levene, que se publica entre 1936 y 1942. El primer volumen de los 24 de esta obra consta de dos partes. La primera, "El hombre prehistórico" y la segunda "Los aborígenes prehispánicos e históricos". Para una discusión acerca de este trabajo de Imbelloni y el estudio de las lenguas indígenas en ese período véase Domínguez, 2019. 
En las páginas que siguen prestaremos atención a estos desarrollos, tomando como base los trabajos realizados en este campo por Bartolomé Mitre y Samuel Lafone Quevedo -particularmente los que giran en torno a la obra del P. Valdivia sobre el allentiac-; a partir de una mirada atenta a los papeles (inéditos) que componen sus propios archivos de investigación (Bert 2014; 2017; Lauvernier 2015). Para esta formulación de una porción de la historia de la lingüística, consideraremos quiénes hablan sobre y desde la lingüística americana en un período específico, de qué manera y cómo se realiza este trabajo (Brigitte Schlieben-Lange 1993 [1983]). Esto implica un movimiento historiográfico que se pregunta por la emergencia de producciones de este tipo en un momento dado y, además, centrarnos en un estudio de estas materialidades, en tanto técnicas intelectuales (Waquet 2015).

En el caso de Mitre, si seguimos la lectura del Catálogo razonado de la sección lenguas americanas (De Mauro 2017; 2018; 2020a) ${ }^{4}$-publicación póstuma en la que organiza los libros y documentos de su biblioteca lingüística americana con comentarios críticos-, podemos marcar algunas de sus preocupaciones persistentes. Esta obra contiene entradas de distinta extensión y con diferencias en la complejidad de su desarrollo, por lo general en forma de discusiones que, en ocasiones, no llegan a cerrarse. Si bien ha sido citada con frecuencia por quienes investigan las lenguas indígenas americanas, como una obra de referencia por la información que contiene sobre ellas, no ha sido analizada como una fuente que condensa los temas, las ideas y la agenda general de trabajo de Mitre en este campo. Entre otros problemas, se destacan en especial las discusiones sobre el carácter general de las lenguas americanas, la ausencia del verbo ser $-\mathrm{y}$, consecuentemente, la (no) abstracción en el sistema de las lenguas americanas-, las filiaciones posibles (entre sí y con otras lenguas conocidas) y los métodos de análisis propuestos para estudiarlas desde el siglo XVI y los últimos años del siglo XIX. Mitre desarrolla estos ejes (aunque a veces de manera superficial) en las entradas de su Catálogo razonado a partir de la crítica a otras obras, realiza análisis cruzando la información entre esas fichas de lectura, e incluye sus propias producciones (De Mauro 2020a).

\footnotetext{
$4 \quad$ El Catálogo razonado de la sección lenguas americanas (1909-1911) es una obra que Mitre realiza, según nuestras investigaciones, en un período de aproximadamente treinta años y que no llega a publicar en vida. Esta obra, como sus otras publicaciones sobre lingüística y arqueología americanas, ha pasado casi desapercibida en comparación con su producción historiográfica.
} 
El cese -aunque no total- de sus ocupaciones políticas hacia 1890, el gran porte de su biblioteca, las adquisiciones de bibliófilo y sus lecturas especializadas, que se dieron en el marco de la red de intercambios entre americanistas (De Mauro 2017; 2020a), son el escenario para la producción de su variado material sobre lenguas y arqueología americanas, como él lo denomina. Así, podemos observar cómo, en la década de los setenta, comienza a difundir textos sobre la temática; en 1878 publica Ruinas de Tiahuanaco, desde una perspectiva más antropológica, que condensa en 1881 con su Ollantay, en el que combina análisis literario y filológico (De Mauro 2020b). Pero es recién entrada la década del noventa cuando encontramos otros trabajos escritos desde una perspectiva que se inserta en los debates de la lingüística americana: "Lenguas americanas. El AraucanoEl Allentiak" (1894), "Lenguas americanas. El Mije y el Zoque" (1895), "Arqueología Americana. Preliminar al examen de la obra de Brasseur de Bourbourg" (1896) y "Lenguas americanas. El tupy egipciano" (1896). A esta producción se agregan una serie de borradores manuscritos (ca. 18941900) de obras en las que estaba trabajando y que no llegaron a publicarse, como "Lenguas patagónicas. Lengua Tehuelche" y "Lenguas americanas. La lengua tehuelche" (Farro y De Mauro 2019; De Mauro 2020a).

Se trata de producciones que emprende a partir de la circulación de distintos tipos de materiales, algún hallazgo bibliográfico, la crítica a otros estudiosos y, particularmente, sobre la base de discusiones entre pares. Como veremos, esto sucede para la confección del artículo sobre el araucano y el allentiac, que escribe con el trasfondo de intercambios constantes con Lafone Quevedo; textos que, además, circulan en la prensa periódica y con distinto alcance.

Por su parte, Lafone Quevedo se dedica-sobre todo desde la década de 1890 - a la comparación de lenguas y dialectos, principalmente del Chaco (las lenguas de las familias mataco-mataguaya y guaycurú) ${ }^{5}$. Sus grandes motivaciones para la compulsa de material, en un comienzo, tuvieron que ver con cuestiones legales de posesión de tierras, ya que "la información contenida en esos documentos probatorios era importante para el desarrollo

\footnotetext{
Siguiendo a Marisa Censabella (1999), la familia mataco-mataguaya "se compone de cuatro lenguas: wichí, nivaclé, chorote y maká. Se trata de una familia de lenguas autóctonas chaqueñas, como las guaycurúes, y todas se hablan en Argentina, salvo el maká, cuyos hablantes viven en una comunidad cerca de Asunción (Paraguay)" (78). La familia guaycurú también es "autóctona de la región chaqueña" y está compuesta actualmente por las lenguas toba, mocoví y pilagá y las ya extintas abipón y mbayá (Ibídem: 60). Según las investigaciones de Viegas Barros (1993), la hipótesis de parentesco entre la familia guaycurú y mataco-mataguayo es muy probable, a partir de "semejanzas que sobrepasan las influencias mutuas en el ámbito de los préstamos” (Censabella 1999: 79).
} 
de las actividades empresarias de Lafone Quevedo, caracterizadas por una creciente diversificación basada en el uso intensivo de la tierra y el agua" (Farro 2013: 530).

La figura de Lafone Quevedo es central en el estudio de la lingüística americana del Sur. En primer lugar, por la vasta producción sobre distintas lenguas indígenas (Farro 2013; Farro y De Mauro 2019; Malvestitti y Orden 2019; Domínguez 2020) y el énfasis que le otorgó a sus investigaciones para el armado de una geografía lingüística del territorio argentino; y, para nuestro caso en particular, por la estrecha vinculación con la biblioteca americana de Mitre (De Mauro 2020a). En este sentido, Lafone Quevedo no solo consulta la gran cantidad de material de que disponía, sino que también se genera un intercambio constante, público y privado, como veremos a continuación.

A partir del recorrido por los intercambios que se realizan entre 1894 y 1895 sobre la Doctrina cristiana y catecismo de la lengua Allentiac (1607) del P. Valdivia, pretendemos mostrar someramente algunas formas de trabajo de dos exponentes de la lingüística americana finisecular en Argentina, desde el análisis de los papeles de trabajo de sus archivos de investigación. Nos proponemos, por un lado, revisar estos materiales con el propósito de aportar a la historiografía lingüística sobre el estudio de lenguas indígenas en nuestro país. Y, por el otro, presentar una forma de trabajo con el archivo que intentará dar cuenta de las distintas materialidades y su vinculación con posturas epistemológicas asociadas a ciertas representaciones ideológicas sobre las lenguas.

\section{UN "HALLAZGO LINGÜÍSTICO"}

Este libro, cuyo título y fecha diversamente anotado y nunca correctamente, se ha considerado por mucho tiempo como un mito bibliográfico habiéndose perdido casi la esperanza de comprobar su existencia. El señor Medina ha prestado un señalado servicio á la lingüística americana al sacarlo del olvido dándole mayor valor [a] los estudios biográficos y bibliográficos con que lo ha ilustrado, en vista de nuevos documentos ${ }^{6}$ Mitre, Catálogo razonado, 1909.

6 En todos los casos, respetaremos la ortografía original de las fuentes. 
Con el "El Araucano y el Allentiak", Mitre cristaliza una forma de investigación en paralelo con Lafone Quevedo, en el contexto de la red colaborativa sobre estos asuntos. Una muestra de esto es la carta que le escribe al primero José Toribio Medina (1852-1930) en 1892, en la que le cuenta que, luego de haber arribado a España, "usted me tiene en mis tareas de costumbre: registrando el Archivo de Indias, las librerías y casa de cambio, en busca de papeles, libros y medallas americanas" (Museo Mitre 1912, III: 287)7. Más adelante, hacia 1894, el chileno le hace llegar a Mitre noticias acerca del hallazgo de una obra del padre Valdivia que se había dado por perdida ${ }^{8}$; aunque ya en 1878 el mismo Medina la había nombrado en su Historia de la Literatura colonial de Chile. Los derroteros de este manuscrito son más que interesantes para seguir los movimientos de este "mito bibliográfico", como lo denomina Mitre en su Catálogo razonado. Como Valdivia también había publicado sobre el araucano (1606), Mitre decide dedicar a ambas lenguas esta investigación que es, sin lugar a dudas, la más extensa y la más completa sobre lingüística americana que escribe. Pero, también, tiene que ver con que pretende estudiar el allentiac en sus posibles relaciones con el araucano ${ }^{9}$.

El recorrido por los intercambios y artículos éditos e inéditos nos indican lo siguiente: Lafone Quevedo hace su investigación sobre la lengua, y el manuscrito de este trabajo está fechado en Pilciao, Catamarca, el 13 y 21 de agosto de $1894^{10}$, ya refiriéndose a la obra del padre Valdivia publicada por Medina. El 3 de agosto de 1894, Mitre le escribe a Lafone Quevedo al respecto y le agradece el envío de sus dos artículos sobre el allentiac que están prontos a publicarse en el diario La Nación. Muy posiblemente se trate de una versión preliminar de las dos entregas publicadas en ese diario: "Arte y vocabulario de la lengua Allentiac (Guarpe). Nueva edición sacada

\footnotetext{
Carta del 8 de diciembre de 1892, en Correspondencia literaria, histórica y política del General Bartolomé Mitre.

8 El padre Luis de Valdivia (1561-1642) S.J. es reconocido como uno de los "evangelizadores de Cuyo". Entre otras obras importantes, en 1606 escribe Arte y gramatica general de la lengua que corre en todo el Reyno de Chile y en 1607 Doctrina cristiana y catecismo con un confesionario, arte y vocabulario breves en lengua Allentiac. La importancia de esta obra radica en que es la única que se conserva sobre la lengua de los huarpes (Sutil 2015).
}

Según Pedro Viegas Barros (2009), "hasta el momento, no ha sido demostrado ningún parentesco de las lenguas huarpes con otras familias lingüísticas o con lenguas aisladas" (p.1). En todo caso, las relaciones con el mapudungun se deben principalmente a los contactos lingüísticos y a los procesos de aimarización y quechuización de estas lenguas durante el Imperio incaico.

${ }_{10}$ Archivo Histórico del Museo de La Plata, colección manuscritos, carpeta $N^{\circ} 50$. 
por el señor Toribio Medina. I. Los Guarpes. Datos históricos; II. La lengua Allentiac y su clasificación" (con fecha 24 de septiembre y 1 de octubre, respectivamente) o puede ser que esa carta de Mitre de agosto esté mal fechada, que es lo más seguro, como veremos más adelante.

\subsection{LOS INTERCAMBIOS ENTRE MITRE Y LAFONE QUEVEDO}

En la mencionada carta fechada el 3 de agosto de 1894, Mitre le dice a Lafone Quevedo:

Con su estimable del 25 del corriente recibí sus dos artículos sobre el Allentiac, que serán publicados en La Nación como Ud. lo desea.

Nuestro amigo J. T. Medina es muy acreedor a nuestro reconocimiento por el que nos presta al exhumar la obra del P. Valdivia sobre el Allentiac, cuya edición se creía perdida, después que desapareció la de la Biblioteca de Lima.

Inmediatamente me puse a su estudio, y he escrito sobre el libro un trabajo, que me ha salido bastante largo, y que publicaré en la "Revista del Museo de la Plata", lo que será agradable a nuestro amigo Moreno, pués el libro de Medina está justamente dedicado a él ${ }^{11}$.

Sobre esta carta comentaremos varias cuestiones. En primer lugar, una referida a la cronología: está fechada el 3 de agosto, pero en el cuerpo Mitre dice que recibió una de Lafone Quevedo "del 25 del corriente" con sus artículos, que de hecho fueron escritos en agosto (13 y 21). Lo más probable, en todo caso, es que la carta sea del 3 de septiembre, si seguimos la sucesión de los hechos, de los manuscritos y las publicaciones. Por otro lado, una cuestión referida a la circulación del material: Lafone Quevedo le encarga a Mitre que publique estos manuscritos en La Nación ${ }^{12}$ y Mitre envía su artículo a la Revista del Museo de la Plata. Esta dinámica de publicación simultánea en revistas especializadas y en la prensa periódica tiene que ver con el tipo de estudio de cada uno: las notas de Lafone Quevedo son mucho más escuetas que el trabajo que ha emprendido Mitre. Pero, por otra parte,

11 Documento 13094, Armario 8, Archivo del Museo Mitre. Para una revisión acerca del papel desempeñado por Medina y la "sociabilidad literaria” rioplatense, véase Sagredo Baeza, 2015.

12 Tengamos en cuenta que, para ese entonces, Mitre ya era dueño de este diario. 
también da cuenta de los tipos de relaciones que se entablan y que se van fortaleciendo en el círculo americanista ${ }^{13}$.

En lo que respecta al contenido del trabajo, Mitre le aclara en esta carta que, más allá de que tenga en cuenta el sistema gramatical y la lexicografía del allentiac, él lo estudia desde otro punto de vista: "me contraigo especialmente a la ideología filológica, es decir, a investigar como pensaban en su lengua los que la hablaban para deducir de esto, su estructura orgánica, su nivel intelectual y comprobar hasta que grado el documento escrito concuerda con esta contraprueba" (el subrayado es nuestro). Le adelanta, también que, al no estar del todo finalizado su trabajo (señala que le falta solo la parte de las raíces), el estudio que le ha enviado Lafone Quevedo en el que éste "sintetiza su teoría sobre la clasificación de las lenguas americanas, según cánones gramaticales que aplica al Allentiac" le es de mucho interés (Ibídem).

A los pocos días, el 22 de septiembre, Lafone Quevedo le envía el manuscrito del "Calepino Allentiac-Castellano" y le informa que está a punto de terminar la traducción de los textos. El 27 de ese mismo mes, Mitre acusa recibo de ese manuscrito y hace mención también del Vademécum, ya que le ha sido muy útil para revisar el vocabulario "que tenía concluido, incluyendo algunas voces que había omitido, y rectificando algunas definiciones". Y, nuevamente, Mitre reflexiona acerca de la manera en que cada uno ha encarado su estudio:

Su trabajo es muy interesante del punto de vista del análisis gramatical, que yo solo toco de paso en el mío, contrayéndome especialmente al análisis léxico, descomponiendo las palabras en sus elementos [...].

La traducción que Ud. está haciendo de las oraciones será de mucha utilidad, por cuanto, poniendo de manifiesto la sintaxis de las lenguas, rectificará las definiciones del vocabulario de Valdivia, que da a las voces proyecciones metafísicas que no tienen, como lo comprueba el texto de la Doctrina ${ }^{14}$.

13 Por ejemplo, Lafone Quevedo le solicita a Mitre que utilice sus contactos para asegurarle un puesto en el Museo de La Plata hacia 1898; por lo tanto en 1894 y entrado 1895, Lafone Quevedo todavía no había forjado una posición lo suficientemente sólida en el centro científico y cultural del país, precisa siempre de Mitre como nexo. Ya más adelante y, sobre todo, pasados los primeros años del siglo XX esto será distinto para Lafone Quevedo: desde 1906 hasta su fallecimiento en 1920 ocupa el cargo de Director del Museo de La Plata. De cualquier manera, se relaciona con Moreno en 1885 y comienza a colaborar con el Museo de La Plata en 1888. Ya desde 1892 es nombrado encargado, con un puesto honorario, de la Sección Arqueología y Lingüística Americana.

14 Documento 13095, Armario 8, Archivo del Museo Mitre. 
Además, menciona allí que le adjunta una página del vocabulario que está haciendo, "que comprende también el estudio de las raíces". Las traducciones, le comenta, las emprende como mero ejercicio para comprobar los desfasajes entre el catecismo y el vocabulario. Para esto, le consulta algunas dudas: "Cómo traduce Ud. la primera parte del Persignar? Como traduce Ud. en el Credo el manichan en la oración "cholup manichan chich". Finalmente, le anuncia que su trabajo está a punto de publicarse ("Nuestro amigo Moreno se ha encargado de la impresión"), en sus dos versiones, como lo conocemos: dentro de la Revista del Museo de La Plata y en separata.

La última frase de la carta es notable por su elocuencia: "Me parece que vamos a resucitar esta lengua muerta, y que nuestros trabajos han de llamar la atención de los filólogos americanistas" (Ibídem). En este recorrido por los intercambios alrededor de la obra del padre Valdivia, se pueden apreciar algunas cuestiones que merecen destacarse. En primer lugar, la discusión sobre los métodos seguidos por cada uno de ellos, asociados a intereses teóricos particulares. En segundo lugar, la reflexión sobre la labor previa de los misioneros y actores que intervienen contemporáneamente en la elaboración de conocimiento acerca de las lenguas. Por último, la atención que ambos colocan a las discusiones y al estado de la cuestión a nivel internacional.

\subsection{EL “ALLENTIAK” DE LAFONE QUEVEDO}

Sin duda alguna la idea que primaria en él [Toribio Medina] sería la de reunir lo mas que pudiese referente á su propio pais, pero esto no ha impedido que se ocupe de buscar y dar á luz un importantisimo opúsculo del mayor interes para la etnologia y la lingüística argentina, nada menos que la reimpresion de la famosa obrita del P. Luis de Valdivia (S. J.) sobre la extinguida lengua de los Huarpes de San Juan y Mendoza, uno de los eslabones que faltaban para completar la cadena de Lenguas Argentinas, tan rica en su importante variedad

Samuel Lafone Quevedo, “Estudio”, 1894. 
Al igual que Mitre, en su trabajo sobre el "Allentiak"15, Lafone Quevedo se sorprende de la labor de Medina, no solo por su esfuerzo y buena voluntad en haberles puesto a disposición la obra del padre Valdivia, sino porque se trata de un hallazgo por demás importante que, de alguna manera, viene a completar su gran empresa: el armado del abolengo de las Lenguas Argentinas. Lafone Quevedo se destaca por la creación de un método clasificatorio propio, como así también por los roles institucionales que comienza a ocupar, cada vez con mayor jerarquía, desde fines del siglo XIX. Estas ocupaciones institucionales, además, propiciaron la profesionalización de su trabajo y redundaron en distintos proyectos como la diagramación de una "geografía histórica de las lenguas indígenas del territorio" a partir de su vinculación con el Instituto Geográfico Argentino, la urdimbre y el montaje de una red editorial para el armado de una Biblioteca Americana o la confección de "Instrucciones" para la recolección de vocabulario de lenguas indígenas para el Museo de La Plata (Farro 2013).

En el mencionado artículo, Lafone Quevedo se lamenta acerca de la ausencia de algún escrito sobre el millcayac, la lengua de los puelches, según su punto de vista; "otra nacion de los indios de la Cordillera", como lee en los escritos del padre Lozano sobre estos, quien además aclara que se trata de lenguas distintas de las que se hablan en todo Chile ${ }^{16}$.

La conclusión a la que llega en la primera parte de su estudio, basado en el escrito del padre Valdivia, es que "el indio cuyano" o los huarpes son una mezcla del "indio del Chaco, con los que acostumbraban a vivir en cuevas, y que sin dudas los precedieron en el pais". Aclara, para finalizar, que lo referido a la "parte étnica" será tratado a partir del estudio sobre su lengua, lo que da paso a la segunda parte de su trabajo.

Para Lafone Quevedo, hay tres cánones para determinar la clasificación de las Lenguas Americanas. El primero debe averiguar

(...) si las particulas de relacion personal, es decir, lo afijos pronominales, se prefijan o se postergan á los temas radicales, en otras palabras, si en el idioma en cuestion se dice mi-casa ó casa-mía; amo, amas, ó o-am, asam. Esta es la diferencia primordial que separa el Quichua del Guarani.

\footnotetext{
15 Nos referimos al manuscrito que nombramos más arriba del "Estudio" que se publica un mes después en La Nación. Las citas que siguen son transcripciones nuestras. La segunda parte de su manuscrito tiene fecha del 21 de agosto y fue publicado el 1 de octubre de 1894 en La Nación.

16 El trabajo sobre el millcayac es publicado recién en 1943 por Fernando Márquez Miranda en la Revista del Museo de La Plata.
} 
Ahora sabemos que los Huarpes estaban encerrados entre Naciones Quichuizantes y Araucanizantes, lenguas eminentemente subfijadoras (que dicen casa-mía y am-as) y las de los Sanavirones y Comechingones, de que nada sabemos, si se exceptua Sacat - Pueblo.

Era de esperarse pues que el Allentiac se resintiese en su gramática con una inclinación a las dos lenguas, la Quichua y la Araucana. Algo de esto se advierte en la morfología de su flexion verbal [...].

Si en la posesivacion de los nombres sustantivos se hubiese procedido del mismo modo, es decir, subfijando las particulas de relacion personal, lo natural y logico hubiese sido clasificar a este idioma como del grupo Andino ó del Pacífico; mas es el caso que el Allentiac, con ser que tiene pronombres de una sencillez apta para subfijos se vale de otro giro que corresponderia á nuestro mí de, tí de, etc (por de mí, de tí, etc.) [...].

Así pues se ve que esta lengua en su posesivacion sustantival se aparte de la morfología Quichua, aymará y Araucana y aun cuando en la fleccion personal de los verbos advertimos una aberracion hacia el grupo subfijador, debe atribuirse á una reminiscencia de uno de dos abolengos.

El segundo canon que advierte debe enfocarse en buscar en las lenguas la palabra que equivalga "al romance agua, como tambien los pronombres y particulas de relacion personal". Con estos datos, ya puede afirmar que esta lengua no es ni fueguina, patagona, araucana, aymara, quichua, atacameña o cacana (según sus propias nominaciones). De todos modos, se trata de una tesis provisional, ya que, como se los conoce hasta el momento, estos idiomas no son "ni puros ni originales". Es decir, cabe la posibilidad de que "contengan rastros y aun más [sean] de común origen con el Allentiac ó algunos de sus factores". Para seguir con las potenciales relaciones de parentesco entre lenguas, sostiene que "falta aun establecer las leyes de las morbosidades fonologicas" y realiza una comparación entre los sistemas pronominales. En relación a esto, señala que:

El Caribe nos enseña empero que una lengua conquistadora es muy tenaz con sus pronombres de 1 ra y 2 da persona, pero que facilmente adopta los de 3ra de la conquistada ó mujeril. Es admisible pues la hipotesis que tengamos en el Allentiac un idioma que á la vez que deba su yo y su tu a un origen Chaquense, tipo Guaycurú, haya adoptado su el de otro emparentado con el Chaquense tipo Lule-Vilela.

Finalmente, el tercer canon con valor clasificatorio para Lafone Quevedo es el denominado "plural doble, de primera persona; uno que excluye, otro que incluye al que oye. Este giro gramatical lo ofrecen en comun las lenguas Quichua, Aymará, Guaraní, Araucana (modificando éste en dual y plural) 
y tambien las de Polinesia”. El allentiac no posee este recurso y, en este sentido, se parece más a las lenguas chaquenses de tipo guaycurú:

Estas lenguas carecen de uniformidad en la voz que usan para designar el agua, asi que ni por este lado se presenta dificultad alguna, mientras que es muy posible que el Caha de los Huarpes resulte encontrarse enredado en esas extraordinarias guturaciones con que los Tobas, Mocovíes y Guaycurúes denominan al elemento de los elementos [el agua].

La observacion nos enseña que en América los pronombres y partículas primordiales pueden parecerse entre una lengua y otra, sin que estas omofonias se hagan extensivas a lo demas de sus vocabularios. El $\underline{\mathrm{Cu}}-$ yo-, y Ca-tú- del Allentiac son en realidad muy parecidos a los sonidos que con igual valor léxico se reproducen en los temas pronominales del Quichua y Chaquense.

Si conociesemos el vocabulario de los indios Trogloditas de Córdoba llamados Comechingones probable es que hallariamos la clave del misterio, puesto que esa vasta region que se extiende desde la Salinas grandes hasta la Cordillera de San Juan y Mendoza y que incluye las Sierras de Córdoba y San Luis, estuvo poblada por indios que habitaban cuevas por casa, sin que por eso algunos de ellos dejasen de preferir la vida nómada y los toldos de estera de los Indios del Chaco.

Es racional pues suponer que cuando la gran invasion de los Guaycurúes del Chaco en que resultó el arrinconamiento de los Lules, Vileleas y otras naciones de habla subfijadora, parte de ellos penetraran á Córdoba y tierra de Cuyo, y allí mezclandose unas y otras veces con los indígenas Trogloditas formaron esas naciones de Huarpes que hablaban la lengua Allentiac.

Con este "Estudio", un primer acercamiento al "Allentiak" del padre Valdivia a partir de su propio sistema de clasificación geográfico-etnológicolingüístico, Lafone Quevedo propone, aunque sea provisoriamente, que las lenguas huarpes no son ni sufijadoras, como el Grupo Andino, ni prefijadoras, como el Grupo Brasiliense. En todo caso, se asemejan a las lenguas del Chaco, que él mismo identifica como Grupo de lenguas mixtas. A su vez, persiste la preocupación por la lengua de los Comechingones y Sanavirones que, para él, también vendrían a ser una pieza importante para completar de manera más acabada la geografía lingüística del territorio argentino.

Así, asegura que, gracias a este libro que dio a luz Medina, pero también a partir de otros apuntes publicados anteriormente por Pelleschi sobre el mataco, el allentiac "esta tan distante de aquel idioma como de todos los demas que hemos detallado y otro tanto puede decirse del $\underline{\text { Uro, }}$, esa lengua de las altiplanicies de Bolivia, sobre la cual debo unas interesantes noticias al Dr. Max Uhle del Museo de Berlin." Como vemos, para Lafone Quevedo, el 
trabajo en red (no solo de hallazgos bibliográficos, sino también de estudios contemporáneos sobre otras lenguas) es primordial para el armado de su cartografía lingüística. Ésta a su vez, entra en relación con su propio sistema clasificatorio que divide a las lenguas entre subfijadores, prefijadoras o lenguas mixtas, a partir de los tres cánones aquí explicados.

\section{3. "EL ARAUCANO Y EL ALLENTIAK” DE MITRE}

Encargóse el padre Valdivia de su catecismo, y valiéndose de tan buena ocasión, se fue informando de su lengua, haciéndose discípulo de unos rudos hombres, el que con tantas ventajas podía ser maestro en las más célebres universidades. Dábales noticias de los misterios de la Fe, y recibíala de las voces y preceptos de aquella dificilísima lengua, sujetándose á decorar sus revesados vocablos, y á ser corregido por los bárbaros, y cuando erraba, ó en la pronunciación ó en el acento, y era la mas de las veces con las risas de los Indios

Mitre, Catálogo razonado, 1909.

El trabajo de Mitre está dividido en tres grandes partes: una primera sobre el araucano, la segunda sobre el allentiac y la última parte que es un "Vocabulario razonado de las raíces del Allentiak" que se trata de una publicación anticipada, con motivo de la aparición del libro editado por Medina "exhumado del polvo del olvido" que además está dedicado a Moreno, "quien con sus exploraciones, investigaciones y publicaciones especiales, tanto ha contribuido al adelanto y difusión de los conocimientos americanos en ambos mundos" (1894: 7). Ahí explica, también, que el motivo de la publicación conjunta sobre las dos lenguas es porque el mismo Valdivia había escrito sobre ambas y, además, según Mitre, porque guardan íntima relación y se complementan, como adelantamos más arriba. La primera pregunta que abre su estudio es la relativa a la familia lingüística del allentiac y las relaciones y afinidades con las otras lenguas

17 La tirada aparte del "Araucano y el Allentiac" es de Talleres de Publicaciones del Museo, año 1894. Además, se publica dentro del tomo VI de la Revista del Museo de La Plata con fecha 1895, pero, en realidad sale primero en la Revista y luego en separata. Las versiones de este trabajo presentan muy pocas diferencias que no resultan significativas para nuestra investigación. De aquí en adelante seguimos la edición en separata de 1894. 
americanas conocidas que, justamente, su libro intentará desentrañar con el estudio del allentiac en relación al araucano.

Acerca del araucano, Mitre disiente con Valdivia en lo que respecta a la aseveración de que la lengua de Chile es una sola. Por el contrario, observa que los mismos datos que proporciona el misionero son la prueba para demostrar que había al menos un dialecto diferente en esa época y que se trata de "un filón de la lingüística que no ha sido explotado"; en este sentido, en el "Arte" como en el "Vocabulario", y especialmente en el segundo, se encuentran "las pruebas de otro dialecto del araucano, que por mucho tiempo se ha considerado como lengua distinta" (Ibídem: 15).

En cuanto al sistema gramatical del araucano, Mitre afirma que el "Arte" de Valdivia se constituyó posteriormente en el modelo para el estudio de esta lengua, sin que necesariamente se haya agregado nada nuevo, aunque sí quizá en lo relacionado con el método "didáctico". Pero, también -y en este punto hará diferencia con los comentarios que reciben las producciones coloniales por parte de los estudiosos decimonónicos-, el trabajo de Valdivia ha reaccionado "por instinto contra el sistema de reducir las lenguas americanas á la norma de la gramática latina, con la cual se les suponían arbitrariamente identidades ó analogías de forma ó de extructura" (18). Así, la base que utiliza el misionero es la propia lengua araucana que luego es descompuesta y analizada "en sus elementos fonéticos y gramaticales, poniendo de manifiesto su mecanismo con claridad y buen criterio" (1819). Además

[Valdivia] Arregla definitivamente su alfabeto, descubriendo en él una sexta vocal, una nueva consonante y varias consonantes modificadas; y guiándose por un seguro método analítico, expone todos los artificios que entran en la composición de los vocablos, tomando por punto de partida sus raíces ó núcleos, y explica cómo intervienen las partículas ó articulaciones, en sus modificaciones, descubriendo entre el singular y el plural la existencia del dual, propio del idioma griego.

El "Arte" del P.Valdivia, considerado en su conjunto, puede decirse que es un tratado sobre el verbo araucano que, como en todas las lenguas americanas, traza el círculo dentro del cual gira el lenguaje, subordinando á él todas sus partes componentes. Esto es lo que constituye la originalidad del trabajo y á eso deberá su duración como el primer monumento escrito sobre la materia (18-19).

Para la segunda parte referida al allentiac, Mitre comienza con un repaso por la historia del documento. En realidad, Medina ya había dado noticias de éste en 1878; se trata de un manuscrito que se hallaba en Lima, pero que al tiempo dieron por desaparecido, como comentamos más arriba. Luego, 
cuando Medina lo encuentra en Madrid en 1894, comienza a resonar el impacto que este hallazgo desata; lo que genera un marcado interés no solo por esta lengua en particular, sino por la lingüística americana en general. En definitiva, para Mitre, se trata de una lengua muerta que, a partir de la aparición repentina de este manuscrito, se la está resucitando filológicamente; como vimos cuando le escribe a Lafone Quevedo, acerca de la atención que recibirá por parte de los americanistas.

Este renacer de la lengua, un "misterio filológico" para Mitre, ha tenido un primer estudioso, Lafone Quevedo, quien "con tanta sagacidad ha hecho la clasificación de las lenguas americanas y especialmente de las argentinas" (1894: 47). Lafone Quevedo, además, la había nombrado en su "Estudio crítico de la raza americana de Brinton" del mismo año (1894). En la parte que sigue, Mitre se enfoca sobre la "lexicología" de la lengua. Así

[e]l Vocabulario Allentiak era abundante en palabras elementales, ó sea núcleos de palabras, si se considera como una lengua de salvajes con pocas necesidades materiales, y sin proyecciones morales, y si se tiene presente lo que dice Muller [...]. Además, debe tenerse en cuenta que el P. Valdivia lo formó por la comunicación oral de unos pocos indígenas emigrados, sin conocer la nación ni sus costumbres, y declara en su título que solo contiene "los vocablos más comunes y necesarios para confesar y catequizar en esta lengua", de lo que se deduce que debía ser en sí más copioso.

Desde luego, se echa de menos en él, la nomenclatura de objetos que debieran conocer aún en su estado de sociabilidad embrionaria, á la vez que abunda en infinitivos abstractos, palabras metafísicas y denominaciones genéricas que no concuerdan con su índole, careciendo en absoluto de términos concretos. Así se vé que, aunque el país que habitaban los Huarpes tuviese su vegetación propia, no trae sinó las denominaciones genéricas de árboles, de hierbas y de flores (en plural), que no aparecen en casos análogos, no incluyéndose de reino vegetal más nombre concreto que el del maíz (70-71).

Finalmente, se puede apreciar que Mitre incorpora en su escrito publicado aquella idea que había desarrollado en su correspondencia con Lafone Quevedo: la "ideología idiomática"18.

Lo que más interesa en una lengua, para darse cuenta de su estructura gramatical y del valor de su vocabulario, es encontrar por inducción,

18 Mitre utiliza indistintamente los términos ideología filológica, lingüística o idiomática. 
los fenómenos intelectuales y morales que pasan en la mente ó en el alma de los que la hablan, á fin de conocer cómo pensaban en ella, ó sea cómo por medio del mecanismo de sus palabras simples ó compuestas, expresaban sus pensamientos y sentimientos y su asociación de ideas. ¿Cómo pensaban los Huarpes en su lengua? Estudiando la composición de algunas de sus frases, y descomponiendo sus vocablos, se sorprende el modo cómo los formaban y la operación mental que ellos traducían.

En este punto, la crítica que Mitre realiza al padre Valdivia tiene que ver con la traducción, ya que el misionero le otorga más abstracciones y complejidad a las palabras de lo que verdaderamente tienen, según su lectura. Para argumentar esto, desarrolla un apartado específico sobre los "abstractos verbales" del allentiac. En consecuencia, el problema del "Catecismo" es que Valdivia tuvo que "interpretar conceptos espirituales, adaptándolos á la inteligencia material del salvaje haciéndole expresar ideas que no estaban en su mente y que eran contrarias á la índole del idioma" (86). Siguiendo esta idea, Mitre traduce algunas oraciones, entre las cuales encontramos la que en la carta de septiembre de 1894 le había consultado a Lafone Quevedo ("cholup manichan chich"). Luego de ciertas pruebas que recoge, concluye:

El Allentiak, como todas las lenguas americanas, debía carecer, y carecía en absoluto de términos abstractos.

Sería una singularidad que una lengua que encierra en su organismo morfológico un círculo muy limitado de asociación de ideas, y que carecía de abstractos y hasta de voces metafísicas y denominaciones genéricas (no obstante que el P. Valdivia le atribuya algunas), tuviese verbales, sustantivos ó abstractos, que expresase de una manera definida el estado ó la acción, sin determinar número ni persona.

Las palabras que pudieran afectar las formas de tales, generalizando una idea, parecerían representar meras acciones reflejas que se derivan de la noción individual. Así se vé, que todo vocablo que parece envolver una idea general (con meras excepciones eufónicas), es invariable, como particularmente se nota en la declinación del nombre, y en la conjugación inflexible del verbo, y particularmente en el verbo típico (quillet) que envuelve la idea de amar, querer (volición), desear y codiciar á la vez, y también la noción de la voluntad en una palabra compuesta, lo que excluye toda concepción filosófica, siquiera sea en el mecanismo gramatical [...].

Como se vé, (quillet=quiero) es el radical invariable, inflexible, del verbo en torno del cual gira toda la conjugación. No es posible concebir que de esta raíz árida, brote la flor del infinitivo, con el gérmen de la idea abstracta de la existencia (88-89). 
En resumen, se puede argumentar que Lafone Quevedo y Mitre son las principales voces en América del Sur que, entre 1894 y 1895, se ocupan de este "hallazgo lingüístico" a partir de una red de actores interesados por diversos aspectos dentro de la americanística y desde un trabajo complementario bien preciso y coordinado. A pesar de esto, se puede apreciar que, tanto sus intereses, como las observaciones que realizan, sus métodos de trabajo y las conclusiones a las que arriban, señalan agendas diferenciadas.

\section{3. "UN MISMO TRABAJO CON DISTINTAS PROYECCIONES"}

En una carta fechada el 12 de enero de $1895^{19}$, Lafone Quevedo le comenta a Mitre que ha recibido un paquete con sus envíos y que ha leído su "Estudio" para anotar algunas impresiones generales. Una de las curiosidades que Lafone Quevedo resalta es que si "Allen" significa "hombre" o "gente" en tehuelche es un argumento de gran peso para la tesis acerca de la derivación de ese nombre; es decir, se trataría de una derivación que no es huarpe. Además, esa "terminación yak ó yag, en Allentiak es el artículo nuestro el ó ella, pero muy posible es que lo sea también en Tehuelche". Por otro lado, también le comenta a Mitre que le ha llamado mucho la atención la cuestión del "aymarismo" de los topónimos en San Juan; característica que él ya ha notado para la región cacana ${ }^{20}$. A partir de esta observación, Lafone Quevedo le asegura que podría darle "más vuelo a estas investigaciones" si él mismo se dedicara a seguir este hilo (1912: 289). Pero, una advertencia en relación con sus avances es que no ha podido realizar aún ninguna comparación con el puelche por la falta de datos y que está a la espera de alguna información al respecto por parte de Moreno. Su interés en este sentido tiene que ver con

19 Esta carta es la única publicada en Correspondencia que coincide con una de las cartas manuscritas que comentamos anteriormente. El manuscrito (documento 14444, Armario 8, Archivo del Museo Mitre) aparece con fecha 12 de enero, pero arriba dice 24 de enero (probablemente la fecha de envío). En cambio, en Correspondencia, esta misma misiva dice "1893", lo cual es evidentemente un error. Si seguimos la cronología de los intercambios, ni el manuscrito puede ser de 1894 ni de 1893, por eso estimamos que Lafone Quevedo anota mal el año, cuando debería haber colocado 1895. Esto se explica si atendemos a la referencia que hace Lafone Quevedo a los números de páginas que corresponden al "Araucano y Allentiak" de Mitre que ha sido publicado a fines de 1894.

20 En 1894, Lafone Quevedo publica un fragmento del Tesoro de catamarqueñismos en el tomo XXXIX de los Anales de la Sociedad Científica Argentina. 
desentrañar si el puelche y el tehuelche son del mismo grupo lingüístico: "espero saber esto para agregar algunos párrafos a mi Vademecum. Así a primera vista dudo que el Tehuelche de Musters y de Moreno tengan mucho en común con el Allentiak" (Ibídem). Estas dudas serán disipadas dos años más tarde, cuando se aboque al estudio de las lenguas fuego-patagónicas; algunos de cuyos manuscritos han permanecido inéditos (Farro y De Mauro 2019) o han sido recientemente publicados (Malvestitti y Orden 2019).

Unos días después, el 5 de febrero de 1895, Lafone Quevedo vuelve a escribirle a Mitre y se alegra de que éste haya aprobado su trabajo. Para Lafone Quevedo, uno de sus primeros fines es que sea de utilidad a aquellos estudiantes de las "Lenguas Americanas", como le sucedió a él gracias a la generosidad de Mitre al abrirle las puertas de su biblioteca. A su vez, afirma lo que éste le dijo antes: "Efectivamente es curioso que Ud. y yo hayamos ideado un mismo trabajo con distintas proyecciones. La idea mia fué de invertir el Vocabulario para poder traducir las Oraciones etc., y hacer en seguida el estudio comparado del idioma. Ud. se dedicaba al estudio lexicográfico así que los dos trabajos vienen a ser útiles apéndices del de Medina." ${ }^{21} \mathrm{Y}$, siguiendo con la circulación del material y la creación del conocimiento sobre las lenguas, Lafone Quevedo le señala:

En estos dias Ambrosetti debe haber mandado a Ud. mi estudio sobre el Lule de Machoni. Es un ensayo del mismo género que el Allentiak y será seguido de otro sobre el Vilela, que tambien se publicará en el Boletin del Instituto Geog. El Allentiak lo reservo para una edicion como la de Ud., dedicada á Medina.

Ya explique a Ud. las dudas que -acerca de que el Tehuelche sea el Puelche aquel de Valdivia. Aquel idioma usa Ya, -'yo'-; Ma -tú-; raíces bien distintas del $\underline{\mathrm{Co}}, \underline{\mathrm{Ca}}$ de nuestro Huarpes. En los numerales no se advierten las analogias que marca Valdivia (Ibídem).

En el Archivo del Museo de La Plata, también hemos hallado una papeleta de apuntes críticos de Lafone Quevedo sobre el tomo VI de la Revista del Museo de La Plata, el número en el que aparece el artículo de Mitre. Para Lafone Quevedo, se trata de un extensísimo trabajo que vendrá a ocupar el lugar de "padrino ante los que desprecian estos estudios, más o menos en la categoria de "cacharros" $y$, sin dudas, esta obra del padre Valdivia es el "acontecimiento" y el "hallazgo lingüístico" del año (1894). Solo que el 
misionero, según sus palabras, se interesó en evangelizar a los "catecúmenos" y para esos fines compuso su Vocabulario castellano-allentiac. En cambio,

[p] ara nosotros que necesitamos estudiar raices y establecer parangones nos era indispensable el Allentiak-Castellano, y á darnos este vocabulario se há dedicado el General Mitre en medio de sus tareas políticas y literarias. Verdaderamente sorprende que haya podido prodigar tanto tiempo y prolija paciencia á un estudio de tal naturaleza: la filologia argentina le deberá este servicio y esperaremos que no sea el último de su clase $\mathrm{c}^{22}$.

Lo interesante de estas notas de Lafone Quevedo es que postulan, en algún punto, justamente lo contrario que Mitre:

Cuan distante esta lo que escribió Azara de la verdad y sin embargo cuantos no habian creido que los Abipones con su lengua eran incapaces de pensar y expresar lo que se contiene en la Doctrina Cristiana.

Yo veo en el Allentiak los restos de una lengua preciosa. El vocabulario es un mero fragmento. ¿Quien puede dudar que la fauna y la flora de ellos tenian sus nombres, como lo mismo todo cuanto usaban ó les servia de algo. Valdivia se limitó á consignar lo que podía dejarle para su enseñanza religiosa, y de lo demas no se cuidaba. El Padre Bárcena, nos cuenta la facilidad con que los Indios Tobas formaban series de palabras para expresar cualquier idea nueva. Somos nosotros los civilizados que matamos la lengua con nuestra pedanteria pidiendo al extranjero lo que muy bien podriamos inventar de lo de casa. El indio procede de otro modo, dadas ciertas raices y ciertos afijos con que cuenta, lo demas es sencillo [...].

El misionero Bridges, con mayor conocimiento de causa les atribuye mas de 30 mil vocablos [a la lengua yagana]. La verdad es que el Allentiak es una de las lenguas Americanas que como el Quichua el Guaraní, el Araucano y el Lule de Machoni tienen su mecanismo gramatical tan sencillo como el Turco, pero á la vez tan capaz de expresar cuanto se le ocurre al hombre como en Latín ó Griego. El Dr. Medina solo hizo imprimir 200 ejemplares del Arte de Valdivia que apenas alcanzarán para satisfacer á sus amigos inmediatos y el General Mitre llena un vacio al generalizar por medio de su artículo el conocimiento de este hallazgo lingüístico (Ibídem. El resaltado es nuestro). 
Como vimos, entre 1894 y 1895, Mitre y Lafone Quevedo intensifican sus comunicaciones sobre lingüística americana impulsados por un "rescate bibliográfico". Las fechas de estas cartas y de las publicaciones por momentos son un tanto confusas y resulta, en ocasiones, complicado determinar con cierta precisión quién comienza a escribir sobre la obra del padre Valdivia. Sí podemos afirmar, en todo caso, que se consolida un mecanismo de funcionamiento que ya era habitual para la época, relacionado con esta red colaborativa. Así, mientras Medina publica su hallazgo y lo da a conocer como una novedad importante, Mitre y Lafone Quevedo utilizan este material como insumo para sus desarrollos críticos; además de basarse en producciones de otros estudiosos sobre diferentes lenguas indígenas. En la correspondencia, cada uno analiza el trabajo del otro y entienden que están realizado un estudio complementario. A lo que le sumamos una apreciación sobre la labor de los misioneros que, en ocasiones, es diametralmente opuesta; como son disímiles también la representación que cada uno tenía sobre estas lenguas. Para Lafone Quevedo se trata de una "lengua preciosa", que fue tergiversada por el padre Valdivia que la recogió con otros intereses. Y, para Mitre, los misioneros fallaron en querer traducir en estas lenguas "proyecciones morales" que los pueblos "salvajes" no podrían tener.

\section{LA RECEPCIÓN Y CIRCULACIÓN DE SUS TRABAJOS}

El libro de Mitre no pasó desapercibido: si la reedición del allentiac del padre Valdivia era vista como un hallazgo lingüístico, para otros, Mitre también "reconstituyó un idioma perdido". Así escribe Ernesto Quesada en un artículo aparecido en enero de 1895 en "El Tiempo", en el que nota que, como dice Mitre en la introducción de su propio texto, este artículo forma parte del catálogo que ya está pronto a publicarse: "Se trata, pues, de un trabajo monumental, á juzgar por la presente muestra. Porque esta monografía sobre el $P$. Valdivia da un volumen de 153 páginas nutridamente impresas. Y este libro no es sino uno de los 300 artículos del "catálogo"”. Así lo supone Quesada, aunque sabemos que el Catálogo razonado ni se publica prontamente como lo anuncia Mitre, ni tampoco consta de trescientos artículos; mucho menos de artículos de este tipo. Por otro lado, según Quesada, la originalidad de esta publicación se relaciona con el hecho de que Mitre hace un trabajo "filológico", a diferencia de Medina que realiza una labor más de carácter bibliográfica. Y en este camino ha tenido un "predecesor de suma competencia", justamente, Lafone Quevedo; quien, 
comenta Quesada, viene difundiendo sus trabajos en la Revista del Museo y en los diarios, y ha estudiado la "faz filológica del asunto" (en los trabajos aparecidos en La Nación, que comentamos). Además, "y esta vez por su sola cuenta- penetra el General Mitre en el terreno de la filología pura"; sección del libro que "merece un aplauso ruidoso, porque revela á un filólogo de conocimientos profundos, faz bajo la cual era poco conocido el autor. Cierto es que se sabía que de años atrás estaba manejando libros sobre lenguas indígenas americanas, pero era valor entendido que lo hacía del punto de vista bibliográfico".

Mitre se encarga particularmente de la distribución y circulación de su obra. En este sentido, en su archivo pueden encontrarse varias misivas cuyo asunto es el envío del libro; como la carta de José Biedma del 5 de enero de 1895 que le agradece le haya hecho llegar su estudio ${ }^{23}$. Y también puede rastrearse el envío del material a instituciones de prestigio internacional como la Académie des sciences morales et politiques, una de las dependencias del Institut de France, acompañado por notas periodísticas sobre la novedad ${ }^{24}$.

El sacerdote e historiador cordobés Pablo Cabrera, por su parte, escribe en 1928 un artículo denominado "Los aborígenes del país de Cuyo", en el que rectifica una parte de la tesis de Mitre. Cabrera sostiene que la ausencia de toponimia en allentiac es aparente. Esto no quita que, según el autor, los trabajos de Mitre, "sabio americanista rioplatense", además de muy importantes para la historia nacional sean más que necesarios para la historia de la lingüística americana.

\section{OBSERVACIONES FINALES: LA LINGÜÍSTICA (SUD)AMERICANA A FINES DEL SIGLO XIX}

Con este recorrido por textos éditos, manuscritos, correspondencia y otros papeles de investigación referidos a la obra del P. Valdivia sobre el allentiac, en los archivos de trabajo de Mitre y Lafone Quevedo hemos pretendido poner en evidencia algunas de las prácticas colaborativas en la producción del conocimiento de la lingüística americana hacia finales del siglo XIX. Más allá de este trabajo mancomunado, hemos señalado la existencia de 
objetivos de investigación diferentes, con maneras distintas de abordar y comprender el objeto de estudio; en las que destacamos, especialmente, posiciones epistemológicas que parten de posturas ideológicas hacia las lenguas indígenas que, en ocasiones, son diametralmente opuestas.

Lafone Quevedo, a partir de su propio sistema clasificatorio, está interesado particularmente en definir y ordenar una geografía lingüística precisa, e intenta desentrañar los arrinconamientos lingüísticos para establecer las relaciones de contigüidad y contacto, a partir de la historia de las poblaciones hablantes de esas lenguas. Eso en cuanto a su objeto de estudio y su forma de abordarlo. Pero, a la vez, mantiene cierta postura sobre la consideración del campo, que nos dice, además, de lo que podía y debía ser estudiado en ese momento. Lafone Quevedo, como vimos, comenta que la lingüística americana era vista como los "cacharros" de la ciencia. Se preocupa-como también se preocupa Mitre-por la llegada y el alcance de las investigaciones americanistas desde América en Europa, particularmente, en el centro de producción de la lingüística decimonónica: "¡Ya verá Ud. si los Alemanes etc. tienen que aprender algo de América!", proclama Lafone Quevedo entusiasmado ${ }^{25}$. Y Mitre arenga: "llamaremos la atención de los filólogos americanistas". Para Mitre, se trata de revivir un tesoro bibliográfico que es el puntapié además no solo para concentrarse en sus últimos años de vida en problemas concernientes a la lingüística americana; sino también una manera de que los avances científicos sudamericanos resuenen al otro lado del océano.

En lo que respecta al trabajo de gabinete y en particular a la utilización de fuentes coloniales, ambos se posicionan frente a la obra de los misioneros, como Valdivia. Se trata de cuestiones relacionadas con el abordaje de la lengua, o mejor dicho, con la traducción y los fines de esas traducciones. Los misioneros tenían el objetivo explícito de evangelizar en las lenguas locales (en un principio), lo que produce, según Lafone Quevedo, poca rigurosidad científica y, para Mitre, traslaciones de esos objetivos a las gramáticas y los vocabularios que generaban.

Mientras Lafone Quevedo ve una "lengua preciosa", con un vocabulario muy copioso, que tiene las posibilidades de decir todo lo que necesita decir esa lengua, Mitre ve lenguas simples, sin capacidad de abstracción que los misioneros traducen mal y les dan un alcance que no tienen. Además, ese vocabulario, según Mitre, tampoco demuestra abundancia, sino en realidad, nuevamente, la imposibilidad de abstracción o de creación de términos 
generales. De cualquier manera, estas posturas bien marcadas, anunciadas por ambos en cada uno de sus textos, y expuestas por ellos en sus intercambios, no es motivo para algún tipo de debate de carácter público al respecto (como sí sucede con otros actores como Vicente Fidel López, Daniel Brinton, Lucien Adam o Brasseur de Bourbourg). Estas diferencias, en todo caso, se mantuvieron en el ámbito de la correspondencia e intercambios de carácter privado; pero, no intervinieron en modo alguno en el trabajo colaborativo. Así, Mitre utiliza las clasificaciones de Lafone Quevedo (pensemos en las hipótesis clasificatorias para el "Allentiak") y Lafone Quevedo también se sirve del vocabulario allentiac-castellano, el análisis de las raíces que hace Mitre para sus hipótesis y por supuesto, del acceso libre a su repositorio documental y bibliográfico.

En la publicación que mencionamos al comienzo, Barros Arana y Lenz (1893) señalan que en las lenguas no hay nada que resulte "indispensable" en su sistema; ya sea lo referido a los mecanismos de un idioma o a sus categorías gramaticales. Estas diferencias, siguiendo sus planteos, no hacen que las distintas lenguas sean ni "pobres, ni tristes, ni monótonas por eso". Y, justamente, ese vacío en la lingüística sudamericana que advierten tiene que ver con la ausencia de producciones que se enfoquen en "la indagacion al mismo tiempo filosófica i lingüística de la manera particular de pensar" y que se desliguen de los modelos latinos (46).

Mitre, por un lado, es consciente de los procesos en los que se "desvirtuaron" los significados de las lenguas por parte de los misioneros, a partir del intento de reconocimiento de las lenguas americanas desde los modelos teóricos válidos para las indoeuropeas (Bixio 2001). Pero, para él, se trata de un ejercicio maniqueo en el que ese disponer nociones occidentalizantes a las lenguas era otorgarles una capacidad que no tienen. En ese sentido, también, Mitre está realizando esa operación que Barros Arana y Lenz reclaman para la lingüística americana: analizar "la manera particular de pensar" o, en palabras de Mitre, "cómo pensaban los indios en su lengua".

Barros Arana y Lenz en 1893 eran conscientes de los grandes avances en cuanto al desarrollo teórico en ese campo en el país del Norte; que se diferenciaba del sudamericano sobre todo por su sistematicidad, impulso, difusión y, básicamente, por el soporte institucional con el que contaban desde comienzos de 1800. Sin embargo, un año después de este diagnóstico, algunos estudiosos se hacen eco de estas faltas y comienza a notarse un importante caudal de producciones en el último decenio del siglo XIX en el hemisferio sur.

Finalmente, a partir del trabajo con dos archivos de investigación sobre lenguas indígenas en la Argentina, pretendemos aportar a la historiografía 
de este campo para un período escasamente analizado o que suele ser concebido como "pre-científico". Muy probablemente esto se deba a que existe una importante cantidad de material inédito o poco conocido que no ha sido analizado aún. La existencia y funcionamiento, a fines del siglo XIX, de redes colaborativas como la aquí descripta -así como el conjunto de prácticas eruditas que la subtienden-, salvo excepciones (Christino 2007), parecen haber pasado desapercibidas para la historia de los estudios sobre las lenguas indígenas en América del Sur.

Siguiendo a Campell (1997) en este sentido, es innegable la contribución que los estudios de las lenguas indígenas norteamericanas han aportado al desarrollo del conocimiento lingüístico en general; cuestión que puede verse en el impacto que ha tenido en el desarrollo de los métodos para investigar las relaciones entre las lenguas, y las teorías en relación a la naturaleza del lenguaje, que influenciaron la manera en la que concibieron las relaciones de parentesco y el cambio lingüístico. En este sentido, para concluir, señalamos la necesidad de continuar profundizando en una cartografía situada y más acabada sobre los desarrollos que tuvieron lugar en el siglo XIX en esta parte del continente americano.

\section{REFERENCIAS BIBLIOGRÁFICAS}

\section{Documentos Consultados:}

Archivo Mitre. Documentos 12401, 14444, 13094, 13096, 14447, 13095, 14446, 14445, 12829 , 14449: correspondencia entre Mitre y Lafone Quevedo. Documento 16201, "Notas sobre la $2^{\circ}$ edición del P. Valdivia". Documento 16208: "Apuntes lingüísticos". Documento 16225: "Apuntes varios".

Archivo Histórico del Museo de La Plata, colección manuscritos, carpeta $\mathrm{N}^{\circ} 50$.

Fuentes (Hasta 1930):

Barros Arana, D. y Lenz, R. 1893. La lingüistica americana. Su historia i estado actual. Santiago de Chile: Imprenta Cervantes.

Lafone Quevedo, Samuel. 1893. La Raza Americana de Brinton. Estudio crítico por Samuel A. Lafone Quevedo. Boletín del Instituto Geográfico Argentino, XIV, pp. 505-528.

Medina, J. T. 1894. Obras del P. Valdivia sobre la lengua Allentiac. Sevilla: Imprenta de E. Rasco.

Mitre, B. 1894. Lenguas Americanas. El Araucano-El Allentiak. Revista del Museo de La Plata. La Plata.

Museo Mitre. 1909-1911. Catálogo razonado de la Sección lenguas americanas. Buenos Aires: Imprenta de Coni Hermanos. 3 volúmenes. 
1912. Correspondencia literaria, histórica y política del General Bartolomé. Buenos Aires: Imprenta de Coni Hermanos. 3 volúmenes.

QuesadA, E. 1895. "Lenguas americanas. Un nuevo libro del general Mitre". Diario El Tiempo, Enero de 1895.

TORres, L. M. (1909). Introducción. En Catálogo razonado de la Sección lenguas americanas. Buenos Aires: Imprenta de Coni Hermanos.

\section{BiBLIOGRAFÍA}

BERT, J-F. 2014. Qu'est-ce qu'une archive de chercheur? Marseille: OpenEdition Press. J.-F. 2017. Une histoire de la fiche érudite. Villeurbanne: ENSSIB.

BIXIO, B. 2001. Lenguas indígenas del centro y norte de la República Argentina (siglos XVIXVIII). En Historia Argentina Prehispánica, tomo II, pp. 875-936. Córdoba: Editorial Brujas.

CAmpbell, L. 1997. American Indian languages. The Historical Linguistics of Native America. Nueva York: Oxford University Press.

Censabella, M. 1999. Las lenguas indigenas en la Argentina: una mirada actual. Buenos Aires: Eudeba.

Christino, B. 2007. A rede de Capistrano de Abreu (1853-1927): uma análise historiográfica do rã-txa hu-ni-ku- i em face da Sul-americanística dos anos 1890-1929. Universidad de Sao Paulo.

De Mauro, S. 2020a. El Catálogo razonado de la sección lenguas americanas de Bartolomé Mitre y la Lingüistica Americana. Tesis doctoral, Universidad Nacional de Córdoba.

S. 2020b. La imposibilidad moral de la existencia del drama: notas sobre la controversia del Ollantay. Anclajes, vol. XXIV, n. ${ }^{\circ}$ 1, pp. 69-86.

S. 2018. El Catálogo razonado de Bartolomé Mitre y la lingüística indígena americana a fines de siglo XIX en Argentina. RASAL, pp. 67-86.

S. 2017. El Catálogo razonado de Bartolomé Mitre: archivo, documentación y redes de coleccionistas sudamericanos. En Actas de las VIII Jornadas Internacionales de Filología y Lingüística, 21 al 23 de junio de 2017, La Plata: FAHCE.

Domínguez, L. 2020. Las lenguas indígenas como contenido curricular: Samuel Lafone Quevedo y los programas de Arqueología americana de la Facultad de Filosofía y Letras de la Universidad de Buenos Aires (1899-1920). Boletín de la Sociedad Española de Historiografia Lingüística 14, pp. 213-236.

L. 2019. Huellas y sustratos. El problema de las lenguas indígenas en el relato antropológico argentino entre 1930 y 1950. Revista Del Museo De Antropología, 12(3), pp. 73-84.

EnNis, J. A. 2018. Las novedosas ciencias del lenguaje y la política de sus usos: Vicente Fidel López en la Revista de Buenos Aires (1863-1869). Boletín de la Sociedad Española de Historiografía Lingüistica, 12, pp. 53-74.

Farro, M. y Sofía De Mauro. 2019. Máquinas de papel y lenguas indígenas americanas. Los archivos de trabajo de Samuel Lafone Quevedo y Bartolomé Mitre. Chuy. Revista de Estudios Literarios Latinoamericanos, [S.1.], v. 6, n. 6, pp. 9-62.

FARro, M. 2018. Ciencias del archivo, lenguas indígenas argentinas y tecnología del papel. Las bibliotecas personales como espacio de producción erudita en la antropología argentina, 1860-1910. En Bibliotecas de las Américas: Poder, capital cultural y circulación de conocimientos, 1800-2000. Lima: Editorial de la Pontificia Universidad de Perú, pp. 225-249. 
M. 2013. Las lenguas indígenas como objeto de colección. Notas acerca de los trabajos lingüísticos de Samuel A. Lafone Quevedo a fines del siglo XIX. Revista de Indias 73, 258, pp. 525-552.

IMBELLONI, J. 1936-1942. Lenguas indígenas del territorio argentino. En R. Levene. Historia de la Nación Argentina: desde los orígenes hasta la organización definitiva en 1862. Buenos Aires: Imprenta de la Universidad de Buenos Aires, pp. 177-350.

LAUVERNIER, J. 2015. Historiographie, archives, artifact. L'archive de la recherché en situation limite. En Bert, J.F.y Ratcliff M.J. (eds.) Frontières d'archives. Recherches, memoires, saviors. Paris: Éditions des archives contemporaines, pp. 145-153.

Malvestitti, M. 2020. El mapuzungun en Puelmapu, entre 1885 y 1945. Territorios eruditos y territorios sociales. Boletín de Filología, Tomo LV, No 1, pp. 51-81.

Malvestitti, M. y María Emilia Orden. 2019. La documentación de las lenguas patagónicas en el gabinete de Samuel A. Lafone Quevedo. El Vocabulario Guenaken. Journal de la société des américanistes, 105-2, pp. 133-164.

Marquez Miranda, F. 1943. Los textos millcayac del P. Luis de Valdivia. Revista del Museo de La Plata, t. II, pp. 61-223.

Orden, M. E. 2017. Descripción de la lengua günün a iajüch. Tesis doctoral, Universidad Nacional del Sur.

Sagredo Baeza, R. 2015. Travesías de un erudito. J. T. Medina y la imprenta en el Río de La Plata. Anales de Literatura Chilena, año 16, n 24, pp. 211-252.

Schlieben-Lange, B. 1993 [1983]. História do falar e história da lingüistica. Campinas: Editora da Universidade Estadual de Campinas.

SutiL, M. 2015. Luis de Valdivia (1561-1642) S.J. Estudios sobre las lenguas de Chile para la intermediación lingüística en los conflictos bélicos. Mutatis Mutandis, vol 8, $\mathrm{n}^{\circ} 1$, pp. 127-147.

Viegas Barros, P. 2009. Una propuesta de fonetización y fonemización tentativas de las hablas huarpes. En http://www.adilq.com.ar (fecha de consulta: 05 de noviembre de 2019).

WAQUET, F. 2015. Introduction. En L'ordre matériel du savoir. Comment les savants travaillent (XVIe-XXIe siècles). Paris: CNRS Éditions. pp. 7-20. 